\title{
HOW MILLENNIALS APPROACH LEADERSHIP IN HIGHER EDUCATION
}

\begin{abstract}
This qualitative study used a phenomenological approach to investigate the perspectives of 11 leaders in higher education. Specifically, we addressed the following research question: How do millennial leaders approach leadership in higher education? The study framework included adaptive leadership as a guide to understand the perspectives of newer leaders within higher education institutions. Our results support a relationship between adaptive leadership and millennial leaders in higher education. They also highlight the importance of leadership mentoring in developing a person's capacity to adapt to constantly changing environments.
\end{abstract}

Keywords: millennial, higher education, leadership

\section{Introduction}

A significant transformation has occurred in higher education institutions (HEIs) over the past decade as rising costs, market and workforce instability, politics, global demographics, and frequent changes in technology affect their sustainability (Hendrickson \& Ikenberry, 2013). Considering the threat of today's challenges, Kezar (2018) described the current climate as complex and characterized by tremendous change. Christensen and Eyring (2011) argued that HEls often seem resistant to change due to their preferences for hierarchy and rigid department structures. Such institutions are particularly vulnerable to disruption if they adhere to antiquated structures that are slow to adapt and prone to rapid depreciation. For example, many academic leaders of HEls often strive to maintain traditions and norms despite the constant pressure to adapt (LeBlanc, 2018).
In the midst of this compelling mix of high stakes and uncertainty, leaders have a timely opportunity to disrupt systems, redefine norms, and examine the role of leadership in higher education (Thompson \& Miller, 2018). Kezar (2018) suggested that institutions need leaders who are change agents and adapt to challenges of this era. Nelson and Squires (2017) argued that organizations need leaders to embrace change, manage crisis, and adapt. Uhl-Bien and Arena (2017) suggested that uncertain and volatile times require adaptive leadership to prepare institutions and their people to cope effectively in a constantly changing environment. The purpose of this study thus was to investigate how millennial leaders in higher education lead in response to tremendous change. Specifically, it aimed to answer the following research question: How do millennials approach leadership in higher education? 
At a time of intensifying pressure on higher education leadership, a unique opportunity exists for transformational change (Kezar, 2018). According to Gagliardi et al. (2017), the average college president is 62 years old. More than half of these presidents are expected to leave their current post in five years or less, which presents an opportunity to diversify the presidency (Gagliardi et al., 2017). As millennials come of age and earn top positions, it is important to understand more about these leaders and how they approach leadership in higher education.

\section{Literature Review}

This study considers the adaptive leadership as a framework to understand the perspectives of HEI leaders. The following topics are integral to understanding the challenges confronting HEls, the role of adaptive leadership in higher education, and the characteristics and roles of millennial leaders in higher education.

\section{Challenges Confronting Higher Education \\ Institutions. As modernization increasingly requires} organizations to adopt new technology, the traditional and sometimes antiquated structures of higher education are proving to be ill-suited for a rapidly changing world (Buller, 2014; LeBlanc, 2018). With origins in 11 th century Europe, these structures often include tiered hierarchies with top-down leadership and multi-level approval processes (Christensen \& Eyring, 2011; LeBlanc, 2018; Mehaffy, 2012). These outdated models often conflict with modern issues, which demand a more egalitarian and equitable approach to higher education. According to Stewart et al. (2018), HEls that prioritize past governance structures over future growth struggle to survive today's challenges.
According to Abdul-Raheem (2016) and Clark and d'Ambrosio (2005), achieving diversity among faculty is a critical challenge facing higher education. As student demographics continue to diversify, there is an increasing need for women and minorities to fill faculty and governance positions. Yet, many HEls are not replacing retiring faculty due to the rising costs associated with tenured employees (Finkelstein et al., 2016; Mehaffy, 2012; Paganelli \& Cangemi, 2019). As examined by Abdul-Raheem (2016) and Hixon et al. (2012), the subsequent loss of open positions directly reduces the diversity of hiring candidates and passively reduces the power of faculty in governing their respective organizations.

One challenge associated with HEI faculty is their continued resistance to the use of digital technology and distance education (Christensen \& Eyring, 2011; Hixon et al., 2012; LeBlanc, 2018). Students today have easy access to information and are accustomed to digital and media-rich learning environments (LeBlanc, 2018). According to Mehaffy (2012), faculty often express anxiety in relation to losing the sanctity of their traditional roles and customary privileges. Furthermore, Hixon et al. (2012) described resistance to technology as a cost to the institution because students prefer HEls that accommodate customized learning opportunities and digital environments.

Adaptive Leadership. Since the early 1990's, adaptive leadership has been researched as a leadership model, theory, and approach to change leadership. Bernstein and Linsky (2016), Heifetz, et. al. (2009), Heifetz and Laurie (1997), and Northouse (2019) believed adaptability was a critical skill because it enabled leaders to change behaviors, feelings, and thoughts in response to environmental demands. Thus, adaptability also enables leaders to discover problems, address change, and challenge people to embrace uncertainty (Northouse, 2019). Leaders lacking the necessary ability to adapt 
might have trouble managing change, developing successful working relations, meeting organizational goals, and enabling the survival of their organizations (Northouse, 2019; Squires, 2015).

Heifetz (1994) defined an adaptive leadership model based on leaders motivating people to respond successfully to changes in the environment. The framework was rooted in the principle that leaders do not have all the answers (Heifetz, 1994). According to Heifetz (1994) and Northouse (2019), many people must participate in solving problems that move the institution forward, and adaptive leaders support the process and prepare the institution for implementation. According to Muluneh and Gedifew (2018), adaptive work was a leadership activity that challenged common beliefs and values, promoted independent judgement, and fostered emotional fortitude, which enabled individuals to sustain longlasting change.

Heifetz and Laurie (1997) created an adaptive leadership theory using six guiding principles that advised leaders to adapt their behaviors to help their people sustain constant change. These principles urged leaders to share responsibility, encourage independence, and welcomed voices from all levels to the table (Heifetz et al., 2009; Heifetz \& Laurie, 1997; Muluneh \& Gedifew, 2018). This approach to leadership provides the necessary skills to navigate change management, form new tactics, and lead institutions through complex environments (Muluneh \& Gedifew, 2018). The six principles are as follows:

- Get on a balcony to leave the situation and see it clearly.

- Identify the adaptive challenge by determining whether a problem has a clear answer, requires a more innovative approach, or both.

- Regulate distress and productivity by maintaining a healthy amount of stress.

- Maintain disciplined attention by focusing on the work to be done and reduce avoidant behavior.

- Delegate effectively by empowering individuals to make decisions and solve problems.

- Promote leadership by encouraging and listening to feedback from all members of the organization, regardless of position or hierarchical status (Heifetz \& Laurie, 1997).

Heifetz et al. (2009) added to the adaptive leadership model and encouraged leaders to leverage three phases to create learning environments conducive to leadership development. Each phase reflects environmental conditions that translates into leadership practice. For instance, fostering adaptation assumes the environment is in flux, necessitating the leader to continuously foster adaption to provide an environment that helps develop their people as leaders. Accordingly, the principles of adaptive leadership as seen in Heifetz et al.'s (2009) threephase approach was used as a theoretical framework to guide the study. The three phases are:

1. Foster adaptation by helping people develop practices that will enable the organization to thrive in a new world.

2. Embrace disequilibrium by keeping people in a state that creates enough discomfort to induce change but not enough to make people freeze or leave.

3. Generate leadership by giving people at all levels of the organization the opportunity to lead.

In other variations, Northouse (2019) and Bernstein and Linsky (2016) described adaptive leadership the values (a) title is not essential to leadership; (b) adaptive leaders accept tasks that are perilous; (c) adaptive leaders distinguish between authority and leadership; and (d) adaptive leaders are followercentered. Bernstein and Linksy (2016) also promoted adaptive leadership as an approach to empower all people to lead regardless of position and as a method that produced leaders able to withstand frequent change.

The aforementioned adaptive leadership theories and models promote change resistance and overall leadership development; however, there are also 
limitations. According to Muluneh and Gedifew (2018), adaptive leaders may spend significant time managing loss and fear associated with changes to staffing and shifting departments. The collaborative culture and rapid change may also cause long-term personnel to feel threatened due to cultural change, constant disruption, and risk of job loss (Bernstein \& Linsky, 2016). Therefore, this approach may promote change leadership but also fail to address the underlying human barriers to implementing drastic change (Bernstein \& Linsky 2016; Muluneh \& Gedifer, 2018; Northouse, 2019).

There is substantial research on the effectiveness of adaptive leadership in corporate settings, however, relatively few studies examine this leadership approach in higher education. Thomas (2016) surveyed the environmental characteristics of two universities that implemented adaptive leadership as an approach to institutional change leadership. The comparative results suggested that adaptive leadership is best applied at HEls that possess a desire to survive; a sense of urgency; a need and desire to change; hands-on, direct involvement of executive leadership; and an active, ongoing response to market forces (Thomas, 2016). Adaptive leadership requires earnestness and a relentless realism to drive change in institutions, and leaders should be able to decipher between essential and non-essential practices across the organization and allot time to focus on essential change (Bernstein \& Linsky, 2016; Heifetz, 1994; Heifetz et al., 2009; Heifetz \& Laurie, 1997; Muluneh \& Gedifew, 2018; Northouse, 2019).

According to Bernstein and Linsky (2016), Buller(2014), and Uhl-Bien and Arena (2017), a shift in mindset regarding the significance of authoritative titles and formalities is a core asset of adaptive leadership. This shift prioritizes people and enables everyone at the institution to contribute. Brue and Brue (2018) and Jenkins (2019) stated that leaders who possess this mindset may see little difference between their role as a person and their role as a leader; moreover, they view leadership as a mental approach rather than a position. Without authoritative barriers, leaders' ability to connect may increase (Buller, 2014; Uhl-
Bien \& Arena, 2017), which in turn may also increase their capacity to motivate people to embrace change and solve difficult problems.

Millennials in Higher Education. Millennials, or those born in the 1980s and 1990s, are characterized as tech-savvy, racially and ethnically diverse, innovative, global-minded, entrepreneurial, and raised in a volatile economy that created a particularly challenging workforce (Brown, 2016; Desilver, 2019). According to the Pew Research Center, millennials now make up the largest proportion of the American workforce (Desilver, 2019). As reported in Faller and Gogek (2019) millennials bring their own attitudes on leadership, work environment, and organizational culture.

Brown (2016) explored the experiences of millennials in executive leadership roles at HEls preparing to modernize their business practices and found experienced employees reluctant to adopt new business practices, such as online application processes and learning management systems. Despite these challenges, millennial leaders have created a new economic and cultural landscape via collaboration, social change, and egalitarianism (Dimock, 2019). Millennials are described in the literature as supportive of technology, possessing diverse communication styles, team-oriented, and as eager entrepreneurs, mentors, and adaptive innovators (Brown, 2016; Lyons, 2015; Weirech, 2017).

\section{Methods and Procedures}

A qualitative phenomenological method was used to better understand the phenomenon of being a leader of a HEl during a time of tremendous change. More specifically, we sought to describe how millennial leaders approach leadership in higher education. As a methodology, phenomenology attempts to gain a deeper understanding of the subject area by 
accessing individuals' lived experiences (Creswell \& Creswell, 2018). We utilized a qualitative approach to assess people, situations, events, and processes that provide connection (Creswell \& Creswell, 2018; Maxwell, 2013). Semi-structured interviews were conducted to explore the perceptions, motivations, and characteristics of selected participants.

Participants. Participants included 11 higher education leaders in the role of vice president or higher who were born between 1980 and 1994 (see Table 1). These participants were selected from small and medium two- and four-year private or public universities. Given the small representation of this population in leadership positions within higher education, we used web searches to identify participants hired within the last two to four years. We identified these institutions as undergoing change through observations of press releases, open leadership positions, or changes to brand identity. We investigated the college leader for potential inclusion against the criteria, and also looked for further evidence of changes in programming, business practices, scope, purpose, or overall strategy to implement practices outside of their historical norms.

\section{Table 1}

\begin{tabular}{ccc}
\hline $\begin{array}{c}\text { Participant } \\
\text { Code }\end{array}$ & Age Range & Current Position \\
VP1 & $37-40$ & Vice President \\
VP2 & $37-40$ & Vice President \\
VP3 & $37-40$ & Vice President \\
VP4 & $35-37$ & Vice President \\
VP5 & $35-37$ & Vice President \\
VP6 & $37-40$ & Vice President \\
P1 & $35-37$ & President \\
P2 & $35-37$ & President \\
P3 & $37-40$ & President \\
P4 & $31-34$ & President \\
P5 & $34-37$ & President \\
\hline
\end{tabular}

Procedures. After securing approval through the institutional review board, potential interviewees were contacted via email to request their voluntary participation in this study. Each interviewee was sent an informed consent that explained the study's purpose and inclusion criteria, as well as details about the interview process. Participants who returned a signed consent form were contacted to schedule a date and time for conducting the interview over the phone. No interview was conducted until a signed informed consent was received from the participant.

The primary researcher conducted the interviews. Prior to each interview, participants were told that they could withdraw at any time without prejudice or penalty. Permission was obtained to record each interview, during which each participant was asked to respond verbally to 12 interview protocol questions. Most interviews lasted between 40 and 50 minutes, though two interviews lasted more than 60 minutes. All interviews were conducted by the primary researcher and audio recorded on a digital recording device. Files were then downloaded onto a password-protected drive on a password-protected computer, after which the files on the digital recording device were deleted. Real names were replaced with participant codes (see Table 1).

Data Analysis. After the initial data collection, the transcripts were analyzed utilizing a qualitative analysis method of assigning codes to units of data. According to Miles et al. (2013) and Moustakas (1994), the use of codes in qualitative research helps researchers to symbolize and give meaning to each piece of data. Initially, the primary researcher coded each interview transcript to identify repeated words and phrases. Using phenomenological reduction methods, the primary researcher condensed the codes into categories. At this stage in the analysis, the secondary researcher served as the peer debriefer and reviewed the initial codes and categories. Both researchers then reduced the codes and categories into thematic statements (Miles et al., 2013; Moustakas, 1994). We also compared our observed themes with those from other studies, such as Brue 
and Brue (2018) and Jenkins (2019), who used a qualitative, phenomenological method to explore phenomena related to leadership.

The analysis processes were influenced by aspects of adaptive leadership. The themes of this study include similar key words and phrases that connect to elements of adaptive leadership. For instance, in Theme 1 of this study, self-development through the development of others, and the third adaptive leadership phase, generating leadership, share relatable descriptors and both focus on generating leadership (Heifetz et al., 2009).

According to Denzin and Lincoln (2017) and Lincoln and Guba (1985) trustworthiness in qualitative research most often refers to data collection and analysis procedures that are plausible, credible, reliable, and defensible. Berger (2015) and Holmes (2020) advised that researchers must be aware of prior knowledge and the impact of their personal biases, beliefs, and personal experiences on their research, and acknowledge and assess how their perspectives influences the research, outcomes, and results.

This qualitative study was conducted by an experienced researcher and a novice researcher. The novice researcher met the study's inclusion criteria, consequently, peer debriefing, member checking, self-appraisal, and reflexivity were used to reduce the influence of bias and partisanship in our findings (Creswell \& Creswell, 2018; Holmes, 2020; Lincoln \& Guba, 1985; Miles et al., 2013). We utilized peer debriefing to leverage our contrasting levels of experience and the risk of bias to help ensure the credibility and trustworthiness of the coding process (Creswell \& Creswell, 2018; Denzin \& Lincoln, 2017). We used member checking, as described in Lincoln and Guba (1985), to provide respondents with opportunities to assess the intentionality and adequacy of the findings. Self-reflection and reflexivity were practiced minimizing bias through consistent self-appraisal and to ensure the independence and rigor of our findings (Berger, 2015).

\section{Results}

After coding and analyzing the data, four major themes emerged regarding how participants approached leadership in higher education: selfdevelopment through the development of others, bold transparency, high tolerance for ambiguity, and commitment to due diligence and data.

\section{Theme 1: Self-Development Through the} Development of Others. Our participants explained that they prepare and motivate people to embrace change by taking a personal, hands-on, and involved approach to personal and professional development. The words "coach" and "mentor" were referenced by several participants to describe their leadership style. For example, a vice president participant (VP6) stated, "Leaders need to empower all people to reach their greatest potential. ... [it] is my job as a leader to coach and build other leaders to make sure that people can get whatever their goals are in life." Another participant described their role as a visionary who empowers and supports their people along their life journeys. When asked about their paths to leadership, several participants credited their own mentors as critical influencers in their trajectory. For example, one of the president participants (P1) stated the following:

I realize the proverbial risk she was taking when she gave me that kind of responsibility. ... I learned everything there was possibly to learn under her tutelage. ... It is my duty to pay it forward. We need young, passionate, knowledgeable advocates leading our institutions. I had many mentors and other people say to me in not so certain terms that so much has been invested in me in terms of my trajectory, so I needed to empower and support people to reach their highest potential. (P1)

In our interviews, participants mentioned how they intentionally push people to work independently and collectively on problem solving, stating that the best way to coach people through change resistance is to break down formal barriers and empower people 
to own the change. Participant P2 said, "We're a team here, so I don't have any followers. I have an expectation that when people come to work, they're empowered to do the job and be the champions of change in their own space." Participant P4 similarly stated,

You have to grow your own leaders from within the organization ... no one starts in a position absolutely perfect. Everyone has a hill to climb, and they need scrapes and bruises to [get to] the next level. My job is to create a culture where people feel like they belong yet are always seeking the next step. ... It is not my job to make leaders feel comfortable in their position but to challenge them to go into new directions and pursue other avenues.

Participant VP2 noted, "I want people to own their work, but not too much ownership so it is able to evolve. ... good leaders want to replace themselves and build upon their legacies as mentors."

The tactic of removing barriers and empowering people to make and own change affords leaders the opportunity to form a plan for succession through relationships with their people. For example, our participants discussed the benefits of mentoring and coaching as a strategy to establish trust, gain support for new initiatives, build relationships, and develop employees' skills. Leaders stated that they view mentorship as a means to train their own replacements and to get the best out of their people. As participant VP6 argued, "Time spent mentoring is sacred, and that time should be set and not changed. ... Don't let anyone dictate your calendar; instead, prioritize your mentees."

Theme 2: Bold Transparency. Our participants described their approach to communication as direct, transparent, honest, open, and frequent. They also used collaborative outlets to promote open communication, including all-campus all-inclusive campus meetings for faculty, staff, and students, weekly team talks, monthly sessions, and other techniques to bring in opinions and concerns from people across the institution. Participant P4 described listening and responding to these messages as a means to:

... gather input and establish trust among people. I want to invite people to push back on ideas and feel like they can be honest. I include all people, at all levels across the institution, so they know what to expect and not to be upset about the uncertainty that comes during a shift or change. I also harness the power of the intelligence and intellectual capital across the system. I think it is vital to solve problems and bring in all those different individuals and teams to accomplish the goal. This helps me figure out where the gaps are and to fill them quickly as possible.

Others discussed the necessity of inclusion in conversations to openly discuss problems and why changes must occur. Participant VP4 discussed using open communication and transparency as part of her regular leadership practice to "get people on board:"

While they may do things because of your hierarchy, you can't really transform unless people have adopted the concept. If you don't bring in everybody in the conversations and decisions are made, you will spend twice the time getting people to say yes when you could have spent less time if you brought them in at the beginning.

Several participants described their leadership preferences as collaborative and inclusive of all people at their HEls. In some cases, participants referenced openness and transparency as parts of a critical strategy to look at situations differently and to help gather data for decision making. Several participants, such as P3, described collaboration as a strategy for creativity and innovation:

Inclusive behaviors, meaning ideas from different types of people, welcome creativity. Leaders need to be open, inclusive, and innovative using the entire team to see the big picture. I think innovation comes from leveraging creative and new ideas. I think the important thing to remember is that everyone has something to contribute.

\section{Theme 3: High Tolerance for Ambiguity.}

Participants discussed how leading in a changing 
environment requires accepting the unknown. Several participants discussed higher education as a rapidly evolving industry. For example, VP6 emphasized the importance of team members continuing a cycle of change:

It's going to change, all of it, always, and they have to be open to that change. ... Everyone on my team knows we're never going to hit the finish line. There's no point where we will say, yes, we did it. Our profession just doesn't work that way. There's always the next level to climb. It's my job to keep them reaching for the next step knowing that they're going to continuously learn and grow. We're always going to be adapting and changing. Education is never going to stop changing.

In planning for uncertain futures, participants were challenged to break old norms and instill flexible cultures in sedentary institutions. Participant P3 stated a willingness to confront and disturb people to challenge their beliefs and behaviors, as well as a need to break down formalities and promote relatability as a necessity to confront traditional culture:

I think that higher education has a history of "ivory tower syndrome," where people think they are larger than life and smaller people below can't go up the tower. It is important for us to meet people where they are and to be relatable. We need to show our students that we have been in their shoes, and if I can do it, you can, too. ... I make it a point to know their names, know what they want to be, and know why they are here. I need them to see me as someone they can be like one day. We simply have to be relatable.

In addition to relatability, participants discussed loyalty, flexibility, and eagerness to change as primary characteristics they looked for in people. Several participants described the immediacy and constancy of change culture. In an attempt to implement necessary cultural changes, participant P1 stressed the importance of urgency as "a time to thrive or die:"

Cultural change doesn't happen overnight, and folks are resistant to change, but we don't have time. I cannot tolerate paralysis of analysis to become an impediment. Right now, I am trying to find out who needs to be on the bus, who is on the wrong bus, and who needs to be off the bus....We are not in the position to wait on people to adapt to the new world. I would rather have someone who is loyal and ready to come along this ride with me than someone who is well-accomplished or carries multiple degrees. I am not willing to keep someone who is unwilling to walk through the storm with me.

Leading in a changing environment creates constant demand for leadership, and participants accordingly described their work as hard with long hours. These leaders describe a desire to create change and their passion to do it. Several participants discussed the challenges of changing past norms and traditions that no longer promote sustainable growth:

When I started at this institution, it was not positioned to hang on another two years. I had to cut programs immediately, reduce staff, cut budgets, fundraise, implement technology, and focus on modern enrollment. I think everyone despised me my first year, and maybe they still do. I made decisions based on research and data. I took risks because we did not have the luxury of being risk averse. You have to work hard. The work is overwhelming. It's pressurized. It is non-stop, literally 24 hours a day. Long nights and every weekend. You have to be 1,000 percent convicted, or you will not make it. I have not been able to do the work-life balance thing and have been going, going, going for a long time. You have to be committed to the students. We don't turn students away, and there is a business consequence. You truly have to be hard-working and fearless. You have to make hard decisions. Mostly, you must realize that everything you do impacts the lives of students, and maybe that thought will carry you through it. (P1)

\section{Theme 4: Commitment to Due Diligence and Data.}

Participants referenced data as a way to assess the current state of their institutions, to prepare for the future, to measure the performance of critical changes, and to gain support from shareholders: 
In my first year, I proposed cutting $40 \%$ of our academic programs. This was a scary prospect for our institution; however, based on research and performance data, cutting these programs would position us for growth. Cutting these programs also defied norms because we would be forced to reduce long-term faculty who have served the institution during my predecessor's 20-year tenure. The concern also came from the potential perspective of reducing positions and drastically cutting expenses. Many of them thought I was making this decision to eradicate the memory of the previous president, which was not even close to the case. As part of the perceived optics and the desire to maintain the face of the institution, many board members were against it, even though data was present to support the change. It is mindsets like these that cannot carry us into the future. (P1)

Participants described the difficulty of balancing these changes while also mitigating the associated risk as they attempted to shift their institutions. They explicitly stated that data and proposed metrics helped to drive conversations:

You must be thoughtful but not impeded by fear when you make decisions. I determine what I need to do or what conversations I need to have based on numbers. For example, if my retention falls to $46 \%$, the data tells me it needs my attention. ... Through the data, I begin to find commonalities and themes. Then that helps me to arrive at what will be the focus on the year or the next three years of the strategic plan. (P2)

Many participants were new to their institutions and expressed that their data-driven strategies reduced the perception that they were implementing changes just for the sake of change. Their approaches to leadership also showed dedication to achieving outcomes. Several participants attributed their success to industrialism, ownership, and the willingness to do whatever it takes. However, most mentioned a lack of work-life balance and divulged that they work extremely long hours:

You must be willing to roll up your sleeves and jump in, not just dictate orders, and get down in the clay and work alongside their leaders; they are more likely to meet the intended outcomes. A leader should share the vision and also work with the team to develop metrics, performance indicators, and really show the team they are truly invested in the work and not just an autocratic leader. They must be willing to invest in the work on the ground, with their leaders, and show them they are willing to do the work themselves. (VP4)

\section{Discussion}

Participants in this study discussed their experience as accelerated and not typical to the career progression of time and tenure traditionally associated with HEls. According to the most recent (2017) American College President Study (ACPS), the typical college president is over 60 years of age and has served as a provost, dean, or VP prior to becoming a president (Gagliardi et al., 2017). Additionally, the majority of all presidents spent an average of 10 years in a faculty role. Considering the chronological age of the participants, millennial representation in these percentages is low. When participants described their accelerated career paths, many paid homages to mentors who helped them to develop both professionally and personally. They described their mentors as willing to invest their time, share their expertise, and take on the responsibilities and risks of generating leadership in young, inexperienced leaders (Heifetz \& Laurie, 1997).

Participants emphasized the benefits of mentoring and coaching upcoming leaders within their institutions as a means to create a new generation of leaders who will eventually be their replacements. This leadership behavior exhibited by participants aligns with Heifetz et al.'s (2009) notion of generating leadership at all levels of the institution. Also, this focus on a leader's intrinsic versus extrinsic gain promotes a sustainable and long-lasting change in people (Muluneh \& Gedifew, 2018). Arguably, this approach to leadership suggests that the participants gained their own sense of self by enhancing development in others and that they placed significant value on 
the roles they played in the lives of their employees. Moreover, according to Khan (2017), this approach has a practical implication, as it enables the leader to also develop loyal employees. Our interviews also revealed that participants focused on mentorship to promote internal development and adaptability, and in so doing, changes in the environment were readily anticipated.

Participants were also willing to forego personal, and at times, professional barriers to connect with others and grow. As Northouse (2019) proposed, this type of leadership behavior provides security for people to develop without fear because they view their leader as a mentor rather than authority. As Bernstein and Linsky (2016) suggested, it may reduce the fear associated with institutional change and helps to shape people into confident, empowered, and highly productive employees. As we observed in our study, this level of personal involvement also allows leaders to be direct and share sensitive information (e.g., budget concerns, cash deficits, and institutional changes) that might otherwise make employees uncomfortable. According to Uhl-Bien and Arena (2017), these types of relationships between leaders and their people can create a greater willingness to withstand rapid change. Our findings also showed that the relationships between participants and their colleagues and employees allowed opportunity to productively and directly address performance concerns.

Many participants described their communication style and decision-making approach as bold and transparent in an effort to facilitate collaboration, which allowed all people to contribute to the overall change or solution. As described in Heifetz et al. (2009), this dynamic is represented as a key part of the disequilibrium phase, which promotes a culture of courage to discuss uncomfortable topics, including those related to change. Northouse (2019) stated that during uncertainty, leaders must be willing to look beyond the issue itself and focus on the underlying factors (e.g., fear, sadness, and incompetence) that caused it.
Heifetz (1994) suggested that under adaptive leadership, people learn to thrive even in highly ambiguous and changeable environments. Many participants in our study mentioned how they communicate with employees by including everyone in discussions, abandoning preconceived notions, brainstorming, gathering data, and conducting trial and error exercises, all of which contributes to innovative solutions. They aimed to involve all people in identifying and implementing solutions because they understand that there is power in collaboration among diverse perspectives. It promotes commitment from a sense of ownership in all stakeholders, which was noted as a key indicator of Heifetz et al.'s (2009) fostering adaptation phase. This leadership behavior, according to Bernstein and Linsky (2016) forces people to confront the potential negative consequences of maintaining the status quo and the benefits of finding solutions to thrive in a new world.

Overall, the responses we recorded from participants portray leaders who are diligent and pragmatic, which aligns with Nelson and Squires (2017) description of adaptive leadership as realistic and thoughtful in a state of continuous change. Participants also stated that they avoid offering assurances or certainty regarding the success of any imposed change, nor do they insinuate that high-stress situations will eventually calm down. This leadership behavior adheres to Heifetz et al.'s (2009) characterization of embracing disequilibrium, which states leaders should stimulate enough discomfort to promote change but not enough to scare people into leaving. In such settings, leaders can probe and identify future challenges while also forcing others to accept that the work can be hard, controversial, and personally distressing.

\section{Future Research}

The findings of this study should be interpreted within a specific context. This sample was limited 
to participants who hold high-level positions, which may limit generalizability. The participants in this study are members of the millennial generation. Perspectives on leadership from older or younger individuals may differ, and future research could explore these differences. Additionally, participants in this study did not participated in the typical HEI career progressions with respect to promotions and tenure, and thus we did not observe a defined path to leadership. Additional research on the purpose and meaning of leadership education with an emphasis on the role of internal development among millennial leaders would greatly benefit the field of leadership education. We plan to conduct additional research on this topic in the future. In particular, we plan to seize the timely opportunity to explore perspectives surrounding the purpose and meaning of internal development during the global pandemic.

Furthermore, Heifetz et al. (2009) developed the phases of adaptive leadership to help leaders seize opportunities to promote leadership development during key moments of institutional change. Northouse (2019) described the lack of specificity surrounding institutional variables may introduce too many unknown complexities to this approach to leadership. Additionally, Heifetz et al. (2009) stated this approach is effective in a wide-variety of institutions and promotes adaptability within people at all levels; however, there is limited empirical evidence to support this claim. Therefore, we believe additional research surrounding its effectiveness within specific institutions would be meaningful and would indicate the environment that may benefit from this leadership approach.

As stated in Bernstein and Linsky (2016), seasoned people may find this approach threatening and offensive due to its casual nature and predisposition to open conflict. For that reason, we recommend further research from the perspectives of leaders belonging to other generations. Also, adaptive leadership promotes voices from all levels of the institution (Bernstein \& Linsky, 2016; Heifetz et al., 2009; Khan, 2017). Therefore, additional research on the perspectives of individuals experiencing this approach leadership would be meaningful to this field of study.

\section{Implications for the Field of Leadership Education}

The responses from participants concerning mentorship implied that millennial leaders are willing to accept the risks associated with shaping and molding their own successors. This leaderfollower relationship encourages both parties to break non-adaptive norms (Bernstein \& Linsky, 2016). As previously mentioned, leaders seek and generate value by developing their team members. The implication for the field of leadership education is that millennials who are entering leadership positions in higher education may naturally develop structures and relationships that foster internal development of personnel. Thus, HEls and programs interested in creating change for these leaders might consider what types of structures and programs foster mentorship as a method to develop leadership skills.

The participants in this study described their worth as inherently tied to who they are, not where they work, what they do, or what they know. In this regard, participants openly accepted that they would make mistakes as they navigate through uncertainty. This acknowledgment may have contributed to their sense of self and their comfort with transparency, boldness, and ambiguity. Their responses indicated that they would not define their self-worth based on the outcomes of their endeavors, whether positive or negative. This mindset represents a shift in perspective from previous generations, who attributed significant value to titles, employers, education, and experience (Buller, 2014). Whereas previous generations distinguished between their professionals and personal identities, the millennials in our study did not note such distinctions. As Jenkins (2019) observed, these leaders believe that their identity is holistic, and that any distinction would be an illusion. 
The participants of our study were leaders of rapidly changing, ambiguous, and complex environments whose current systems are unstable. Many people seek direction during such uncertainty. Heifetz et al. (2009) argued that the organizational adaptability required to meet a relentless succession of challenges is beyond anyone's current expertise. This shift necessitates an emphasis on context within the institution. Leaders must adapt to their institution and then manifest a leadership style based on organizational needs to find a path forward through the uncertainty. Adaptive leaders act and react appropriately based on the place and time. This approach may not always match the leaders' preferences; nevertheless, they must find a path forward even when the leadership role feels less natural. For instance, during the initial COVID-19 pandemic, the recommendations and guidelines changed hourly at times. This highly uncertain circumstance required leaders to offer guidance, even when such guidance was unclear or unavailable. They also had to make decisions with little to no collaboration or consensus. During such times, the adaptive leader can rise to the occasion. 


\section{References}

Abdul-Raheem, J. (2016). Faculty diversity and tenure in higher education. Journal of Cultural Diversity, 23(2), 53-56. https://search.proquest.com/scholarly-journals/faculty-diversity-tenure-higher-education/ docview/1795672454/se-2?accountid=201395

Berger, R. (2015). Now I see it, now I don't: Researcher's position and reflexivity in qualitative research. Qualitative Research, 15(2), 219-234. https://doi.org/10.1177/1468794112468475

Bernstein, M., \& Linsky, M. (2016). Leading change through adaptive design. Stanford Social Innovation Review, 14(1), 48-54. https://doi.org/10.18844/prosoc.v5i4.3701

Brown, S. (2016). When millennials become managers. Chronical of Higher Education, 62(41), 3. https://www. chronicle.com/article/when-millennials-become-managers/

Brue, K., \& Brue, S. (2018). Leadership role identity construction in women's leadership development programs. Journal of Leadership Education, 17(1), 7-27. https://doi.org/10.12806/V17//1/C2

Buller, J. (2014). Change leadership in higher education: A practical guide to academic leadership. Jossey-Bass.

Christensen, C., \& Eyring, H. (2011). The innovative university: Changing higher education from the inside out. Jossey-Bass.

Clark, R., \& d'Ambrosio, M. (2005). Recruitment, retention, and retirement: Compensation and employment policies for higher education. Educational Gerontology, 31(5), 385-403. https://doi. org/10.1080/03601270590921663

Creswell, J., \& Creswell, J. (2018). Research design: Qualitative, quantitative and mixed methods approach. Sage Publications.

Denzin, N., Lincoln, Y. (2017). The sage handbook of qualitative research. Sage Publications.

Desilver, D. (2019). 10 facts about American workers. Pew Research Center. https://pewrsr.ch/2Zm7e8Y.

Dimock, M. (2019). Defining generations: Where millennials end and generation Z begins. Pew Research Center. https://pewrsr.ch/2szqtjz.

Faller, M., \& Gogek, J. (2019). Break from the past: Survey suggests modern leadership styles

needed for millennial nurses. Nurse Leader, 17(2), 135-140. https://doi.org/10.1016/j.mnl.2018.12.003

Finkelstein, M., Conley, V., \& Schuster, J. (2016). The faculty factor: Reassessing the American academy in a turbulent era. John Hopkins University Press.

Gagliardi, J., Espinosa, L., Turk, J., \& Taylor, M. (2017). American college president study 2017. American Council on Education. https://www.acenet.edu/Research-Insights/Pages/American-College-President-Study.aspx

Muluneh, G., \& Gedifew, M. (2018). Leading changes through adaptive design. Journal of Organizational Change Management, 31(6), 1249-1270. https://doi.org/10.1108/JOCM-10-2017-0379

Heifetz, R. (1994). Leadership without easy answers. Harvard University Press. 
Heifetz, R., Grashow, A., \& Linsky, M. (2009). Leadership in a (permanent) crisis. Harvard Business Review, 87(8), 62-70. https://doi.org/10.1037/e563252009-001

Heifetz, R., \& Laurie, D. (1997). The work of leadership. Harvard Business Review, 75(1), 124-134. http://www. nhcue.edu.tw/ aca/fte/95-2/4.pdf

Hendrickson, R., \& Ikenberry, S. (2013). Academic leadership and governance of higher education: A guide for trustees, leaders, and aspiring leaders of two- and four-year institutions. Stylus Publishing.

Hixon, E., Buckenmeyer, J., Barczyk, C., Feldman, L., \& Zamojski, H. (2012). Beyond the early adopters of online instruction: Motivating the reluctant majority. The Internet of Higher Education, 15(2), 102-107. https://doi.org/10.1016/j.iheduc.2011.11.005

Holmes, A. (2020). Researcher positionality: A consideration of its influence and place in qualitative research. Shanlax International Journal of Education, 8(4), 1-10. https://doi.org/10.34293/education. v8i4.3232

Jenkins, D. (2019). Exploring the lived experiences of becoming and being a leadership educator: A phenomenological inquiry. Journal of Leadership Education, 18(3), 141-154. https://doi.org/10.12806/V18/ $\underline{\text { I3/R10 }}$

Kezar, A. (2018). How colleges change: Understanding, learning, and enacting change. Routledge.

Khan, N. (2017). Adaptive or transactional leadership in current higher education: A brief comparison. International Review of Research in Open and Distributed Learning, 18(3), 178-183. https://doi.org/10.19173/ irrodl.v18i3.3294

LeBlanc, P. (2018) Higher education in a VUCA world. Change: The Magazine of Higher Learning, 50(3-4), 23-26. https://doi.org/10.1080/00091383.2018.1507370

Lincoln, Y., \& Guba, E. (1985). Naturalistic inquiry. Sage Publications.

Lyons S., Schweitzer, L., \& Ng, E. (2015). How have careers changed? An investigation of changing career patterns across four generations. Journal of Managerial Psychology 30(1), 8-21. https://doi.org/10.1108/ JMP-07-2014-0210

Maxwell, J. (2013). Qualitative research design: An interactive approach. Sage Publications.

Mehaffy, G. (2012). Challenge and change. EDUCAUSE Review, 47(5), 25-42. https://er.educause.edu/ articles/2012/9/challenge-and-change

Miles, M., Huberman, M., \& Saldana, J. (2013). Qualitative data analysis: A methods sourcebook. Sage Publications.

Moustakas, C. (1994). Phenomenological research methods. Sage Publications.

Nelson, T., \& Squires, V. (2017). Addressing complex challenges through adaptive leadership: A promising approach to collaborative problem solving. Journal of Leadership Education,

16(4), 111-123. https://doi.org/10.12806/V16/l4/T2

Northouse, P. (2019). Leadership: Theory and practice. Sage Publications. 
Paganelli, A., \& Cangemi, J. (2019). Effects of aging faculty. Education, 139(3), 151-157. https://www. davidlynchfoundation.org/pdf/quiet-time-research/Quiet-Time-on-Social-Emotional-Learning. pdf\#page $=47$

Stewart, B., Khare, A., \& Schatz, R. (2018). Volatility, uncertainty, complexity, and ambiguity in higher education. Springer International Publishing, 1, 241-250. https://doi.org/10.1007/978-3-319-16889-0_16

Nelson, T., \& Squires, V. (2017). Addressing complex educational challenges through adaptive leadership: A promising approach to collaborative problem solving. Journal of Leadership Education, 16(4), 111-123. https://doi.org/10.12806/V16/l4/T2

Thomas, B. (2016). Characteristics of higher education environments conducive to adaptive change (Publication No. 10239820) [Doctoral dissertation, Azusa Pacific University]. ProQuest Dissertations and Theses Global.

Thompson, M., \& Miller, K. (2018). Disruptive trends in higher education: Leadership skills for successful leaders. Journal of Professional Nursing, 34(2), 92-96. https://doi.org/10.1016/j.profnurs.2017.11.008

Uhl-Bien, M., \& Arena, M. (2017). Leadership for organizational adaptability: A theoretical synthesis and integrative work. The Leadership Quarterly, 29(1), 89-104. https://doi.org/10.1016/j.leaqua.2017.12.009

Weirich, B. (2017). A millennial leader's view on the millennial workforce. Nurse Leader, 15(2), 187-139. https://doi.org/10.1016/j.mnl.2016.12.003 